\title{
LA CONSTRUCCIÓN DE FUENTES PARA RECONSTRUIR LA HISTORIA DE LOS MEDIOS EN LA PROVINCIA DE MISIONES: EL DOCUMENTAL COMO RESCATE DE LA HISTO- RIA Y MEMORIA DE LA TELEVISIÓN.
}

\author{
JORGE NELSON PYKE \\ Universidad Nacional de Misiones, \\ Posadas, Misiones, Argentina \\ e-mail: jorgepyke@hotmail.com
}


A CONSTRUÇÃO DE FONTES PARA RECONSTRUIR A HISTÓRIA DOS MEIOS NA PROVÍNCIA DE MISIONES: O DOCUMENTAL COMO RESGATE DE HISTÓRIA E MEMÓRIA DA TELEVISÃO

Resumo: A construção da história da televisão em Misiones foi alcançada a partir dos testemunhos orais daqueles foram incorporados ao meio em suas origens. Então, a gente fez um documentário sobre a participação de LT85 Canal 12 durante o conflito das Malvinas começou em 02 de abril de 1982. Oobjetivo desteartigoéanalisarerefletirsobreaspossibilidadesoferecidaspor essas fontes para reconstruire aprendera história da mídia no passado recente Palavras-chave: Fonte oral; metodologia; documentário; historiografia; fronteira.

\section{LA CONSTRUCCIÓN DE FUENTES PARA RECONSTRUIR LA HISTORIA DE LOS MEDIOS EN LA PROVINCIA DE MISIONES: EL DOCUMENTAL COMO RESCATE DE LA HISTORIA Y MEMORIA DE LA TELEVISIÓN.}

Resumen: La construcción de la historia de la televisión en Misiones se logró a partir de los testimonios orales de quienes se incorporaron a ese medio en sus orígenes. Así, realizamos un documental sobre la participación de LT85 Canal 12 durante el conflicto de Malvinas iniciado el 2 de abril de 1982. El objetivo del presente artículo es analizar y reflexionar sobre las posibilidades que nos brindan estas fuentes para reconstruir y conocer la historia de los medios en el pasado reciente. Palabras claves: Fuente oral; metodología; documental; historiografía; frontera.

THE CONSTRUCTION OF SOURCES TO REBUILD THE HISTORY OF THE MEANS IN THE MISIONES PROVINCE: THE DOCUMENTARY AS RESCUE OF HISTORY AND MEMORY'S TELEVISION

Abstract:The construction of the history of television in Misiones was achieved from the oral testimonies of those were incorporated into the medium in its origins. So, we made a documentary about the participation of LT85 Channel 12 during the Malvinas conflict started on April 2, 1982. The aim of this paper is to analyze and reflect on the possibilities offered by these sources to reconstruct and learn the history of the media in the recent past. Keywords: Oral source; methodology; documentary; historiography, border. 


\section{INTRODUCCIÓN}

Una de las características distintivas de la provincia de Misiones la da su situación de región fronteriza, multiétnica y por ende multicultural. Esta pequeña provincia ubicada lejos de los grandes centros urbanos del país, contaba desde fines del siglo XIX con una variada e interesante cantidad de medios de comunicación. Así, se sucedieron diferentes emprendimientos comunicacionales que abarcaron medios gráficos, radiales y televisivos. El desarrollo de la provincia fue acompañado por estos medios que en cierto modo buscaron construir una identidad nacional con un fuerte acento territorial. En este proceso, la ubicación geográfica; la cuestión de la frontera; la composición de la población y el acceso a las nuevas tecnologías, aparecieron -en distintos momentos históricos - como variables significativas que no deben dejar de ser tenidos en cuenta a la hora de analizar el rol que se le asignó a los medios en la comunidad, y los usos que esta comunidad hace / hizo de esos medios. Es en este contexto que desde comienzos del 2010, un grupo de comunicadores sociales e historiadores decidimos iniciar un proyecto de investigación sobre la historia de los medios de comunicación en la provincia de Misiones. Surgió así el primer proyecto titulado "Historia de los medios de comunicación de Misiones: LT 85 TV Canal 12, el canal de TV de los Misioneros"17. En términos generales, el proyecto analizó el rol que jugaron los medios de comunicación en la construcción de nacionalidad, identidad y ciudadanía; sobre todo, en la etapa de implementación de políticas comunicacionales desde el Estado Nacional, en donde la televisión ocupó un lugar preponderante en la construcción de soberanía y argentinización de su población en provincias fronterizas como la de Misiones. Estos acontecimientos caracterizaron a la década de 1970 y englobaron a la creación de la televisión pública en Misiones en un período historiográfico conocido como "historia reciente". En tal sentido, trabajar períodos históricos que abarcan los últimos cuarenta años del siglo XX constituye un verdadero desafío para los historiadores. ¿En qué sentido? Básicamente en el acceso a las fuentes escritas y fílmicas ya que la gran mayoría fue destruida o, en el mejor de los casos, se halla incompleta o en condiciones que requieren determinados procesos de restauración. Construir la historia de la televisión misionera requiere la utilización de una variada gama de técnicas meto-

17 Actualmente estamos trabajando en el proyecto Historia de los medios de comunicación de Misiones: Los inicios de la TV por cable. El caso de Canal 2 de Posadas. 
LA CONSTRUCCIÓN DE FUENTES PARA RECONSTRUIR LA HISTORIA DE LOS MEDIOS EN LA PROVINCIA DE MISIONES: EL DOCUMENTAL COMO RESCATE DE LA HISTORIA Y MEMORIA DE LA TELEVISIÓN dológicas historiográficas. Principalmente estamos refiriéndonos al uso de las fuentes orales. Esta técnica de recolección de datos nos resulta la más conveniente cuando se trata de reconstruir la historia reciente de la televisión. Por tal motivo, nuestro proyecto de investigación da fundamental importancia a esta forma de construir fuentes orales y fílmicas. En tal sentido, realizamos un documental referido a un episodio relevante en la historia de LT85 Canal 12. Se trata de la participación que tuvo este medio durante el conflicto de Malvinas que se inició el 2 de abril de 1982. El presente trabajo pretende analizar y principalmente reflexionar acerca de las posibilidades que nos brindan estos tipos de fuentes, sin perder de vista los problemas teóricos y metodológicos que se desprenden de su utilización para la investigación histórica de los medios de comunicación en el pasado reciente.

\section{Una aproximación metodológica: el problema de incluir tes- timonios orales}

El trabajo con fuentes orales dentro de la investigación histórica constituyó una "novedad metodológica" que surgió con fuerza a partir de la segunda mitad del siglo XX. La pregunta que dispara el problema podría ser ¿Por qué defender la inclusión de testimonios orales en la investigación histórica? Existen respuestas variadas a esta pregunta que tiempo atrás (poco tiempo) desvelaba a muchos historiadores. Debemos considerar que estamos ingresando en la segunda década del siglo XXI y es evidente que el problema tiende a traspasar los límites estrictamente técnicos o metodológicos y se suele instalar en terrenos de la política, la ética y en la propia teoría social. Los acontecimientos históricos cargan imágenes y sonidos que involucran a los sujetos que los protagonizan. La historiografía tradicional, utilizó básicamente fuentes escritas recogidas de archivos o periódicos de la época. Tal como lo afirmamos más arriba, tratándose de hechos históricos relacionados a lo que se conoce como "historia reciente", debemos tener conciencia de la necesidad de contar con testimonios orales/fílmicos que entrecrucen nuestra investigación documental. En tal sentido, como investigadores sociales, no podemos obviar que de existir el testimonio, esa información se estaría perdiendo si encaramos nuestro proyecto desde una perspectiva historiográfica puramente tradicional. Actualmente, es necesario contar con una dosis de subjetividad proveniente de los propios protagonistas de los acontecimientos a describir y explicar. Ahora bien, el trabajo 
así encarado nos plantea otro interrogante: el grado de fiabilidad y certeza que le podemos dar a este tipo de testimonio. No obstante, desde el punto de vista metodológico propiamente dicho, se hace más que necesario incorporar a las fuentes orales para el estudio e investigación de sucesos cuyos protagonistas aún viven. Vera Carnovale (2007) plantea algunos interrogantes: "¿cómo incorporar al relato histórico un acontecimiento sobre el cual los periódicos nada dicen y la memoria 'falla'? ¿Debemos suponer que el 'hecho' nunca tuvo lugar? Sería absurdo hacerlo: la ausencia de algún registro de época no es argumento suficiente para la negación de lo que 'efectivamente ocurrió'; no podemos pretender que la totalidad de los acontecimientos quede registrada indefectiblemente en periódicos y otro tipo de documentación" (Carnovale, 2007:157)

Es innegable que el saber histórico posee dimensión textual. Así, la escritura de la historia se convierte en una práctica discursiva que, tal como señala Enzo Traverso, incorpora una parte ideológica que supone representaciones y códigos literarios heredados que se pueden visualizar en el itinerario individual del autor (Traverso, 2011). El discurso histórico tiene la intención de incluir siempre un contenido verdadero, pero siempre bajo la forma de una narración. Ahora bien, volviendo a cuestiones metodológicas, durante mucho tiempo la historiografía descansó sobre una supuesta "autosuficiencia" de los hechos. Fue así que los archivos se convirtieron en las principales (y tal vez únicas) fuentes para el historiador. Sin embargo, tales fuentes no constituyen un reflejo neutro y objetivo de la realidad que pintan: también pueden mentir. Por tal motivo, dentro de la preceptiva metodológica de los historiadores existe el trabajo de decodificar e interpretar las fuentes y en el caso de que estas falten o resulten escasas, construirlas.

\section{La tecnología y la historiografía frente a la construcción de fuentes orales/visuales}

Desde fines de la década de 1940, historiadores, etnólogos, sociólogos y antropólogos norteamericanos, ingleses y franceses trabajaron dentro del marco metodológico con lo que llamaron oral history ${ }^{18}$. Todas sus investigaciones estaban atravesadas por el uso de testimonios orales. Pero el uso de estos testimonios puede presentar objetos y categorías diferentes. 

RIA DE LOS MEDIOS EN LA PROVINCIA DE MISIONES: EL DOCUMENTAL COMO RESCATE DE LA HISTORIA Y MEMORIA DE LA TELEVISIÓN

Este recurso tendrá sentidos diferentes según las tradiciones intelectuales de quienes lo utilicen ${ }^{19}$. Para los historiadores, trabajar esta técnica se relaciona directamente con la construcción de archivos orales/visuales. La tarea principal consiste en crear repositorios que sirvan para los investigadores futuros y que presenten reglas particulares para su elaboración. Así, es necesario tener en cuenta algunos principios metodológicos elementales que rigen la constitución de estos nuevos documentos. Desde un punto de vista técnico, la base de todo testimonio oral recogido por los investigadores es la entrevista. ¿Qué es la entrevista? De por sí, no constituye la gran panacea, recoge cierto tipo de información en medios sociales y en ciertas situaciones. La técnica permite conservar y transmitir historias, describir los gestos de un oficio, de la vida cotidiana y más en general lo que por su carácter no deja huellas escritas o deja muy pocas. La entrevista de historia oral, mediada por el uso de una tecnología básica (en principio una grabadora) permite recuperar documentos reconstruyendo la forma en los sujetos sociales han vivido determinadas situaciones. En este sentido, el producto de la entrevista puede hacer revivir el detalle de la vida cotidiana: lo "vivido" por el informante ("la historia haciéndose") ²0. La relación que establece la entrevista es social y entre dos individuos con posiciones sociales determinadas. Es una relación desigual debido a que uno de los individuos tiene la prerrogativa de interrogar. Esto se puede acentuar teniendo en cuenta la diferenciación social entre el entrevistador y su entrevistado, obliga al entrevistador a realizar un verdadero trabajo de introspección que le permita ejercitar el "arte" de saber escuchar con humildad y sin juzgar, guardar una cierta simpatía sin que ello implique participación alguna. La práctica de esta técnica requiere de una vigilancia epistemológica por parte del investigador, una actitud de profunda reflexión que le haga sentir a su entrevistado que está siendo escuchado con atención, que no está siendo evaluado, aprobado o condenado. Existen ciertas reglas simples que con la práctica

19 Para etnólogos y antropólogos siempre fue material básico, los sociólogos oscilaron entre un manejo cuantitativo y/o cualitativo de sus datos y para los historiadores constituye toda una novedad.

20 Hablamos aquí de las diferentes significaciones que los actores dieron a su acción y a la de los otros. En tal sentido, las fuentes escritas son limitadas tratándose de conocer a las personas y a sus relaciones interpersonales. Se puede conocer de esta forma muchos hechos olvidados, evidencias de lo que podríamos llamar: "lo invisible cotidiano" (Aceves Lozano, 1993). 
se convertirán en el habitus de todo investigador que trabaje construyendo fuentes orales ${ }^{21}$. Realizar entrevistas tal vez no constituya de por sí un "arte", pero es una práctica en la que el investigador se educa con trabajo y adquiere experiencia. El investigador social, como entrevistador, adquiere diferentes niveles de responsabilidad frente al documento que está co-creando. Así, un sociólogo debe mantener el secreto del anonimato de sus informantes. Quienes organizan archivos orales institucionales, en algunos casos puntuales amparan y resguardan la información bajo un sistema que permiten hacerlos públicos dentro de un lapso de tiempo predeterminado. Aquellos historiadores que requieren utilizar en forma rápida el documento, deberán obtener la respectiva autorización para publicar la información.

En esta cogestión, la confianza va de la mano con el uso de la grabadora y/o filmadora que le darán un peso suplementario a las palabras dichas. Pero debemos tener en cuenta que la utilización de estos elementos pueden ocasionar reticencia en el entrevistado. Este impacto será menor si el informante percibe estos dispositivos como un instrumento más de trabajo del entrevistador. En nuestro caso, muchos de los entrevistados se han desempeñado o aún se desempeñan en medios de comunicación por lo que la tarea de entrevista con grabadora y filmadora no limita la información, en cierta forma contribuye a que el entrevistado se sienta "a gusto" con la conversación. Desde finales de la década de 1970, la utilización de cintas grabadas representó una gran novedad en la utilización de fuentes orales. La tecnología (grabadoras, filmadoras y otros dispositivos) pasa a reemplazar a los discursos reconstruidos según la lógica de la historiografía tradicional o a las referencias de testigos oculares que los historiadores recibían a través de documentos que no reflejaban en su totalidad las vivencias.

\section{Los juegos de la historia y la memoria en imágenes}

A mediados de 1980, el film Shoah dirigido por Claude Lanzmann marcó un hito importante, no sólo en lo referente al genocidio judío como "acontecimiento" sino en integrar el testimonio como fuente del conocimiento

\footnotetext{
21 Discreción, no prejuzgar ni juzgar, permitir que la memoria del informante fluya lo más libre que sea posible e incluso ayudándolo a recordar, orientándolo, evitar preguntas directas (policíacas) no usar palabras cargadas de subjetividad o palabras con las que el entrevistado no esté familiarizado. Insistir sobre los detalles, pedir ilustraciones lo más precisas posibles, aclarar expresiones ambiguas
} 

RIA DE LOS MEDIOS EN LA PROVINCIA DE MISIONES: EL DOCUMENTAL COMO RESCATE DE LA HISTORIA Y MEMORIA DE LA TELEVISIÓN

histórico. A partir de ese film, los trabajos sobre la memoria recibieron un fuerte impulso. Tal como lo señala Traverso: “... sin duda no sería exagerado afirmar que el estatus del testimonio en la investigación histórica no fue el mismo luego de esta obra." (Traverso, 2011: 66) Más allá de los interesantes debates que suscitó dicho film, nos interesa puntualizar la compleja relación que la historia establece con la memoria. De este modo, nuestro proyecto de investigación comenzó con la construcción de la historia de LT 85 TV Canal 12 de Posadas. Uno de los objetivos que nos propusimos fue rescatar la memoria de aquellos sujetos que tuvieron una activa participación dentro de la historia de los medios de comunicación de la Provincia de Misiones. Desde el punto de vista metodológico, nos encontramos con un problema: la inexistencia de un cuerpo documental sistematizado, es decir, fuentes guardadas en archivos públicos o privados. Dicho problema nos llevó a un esfuerzo de construcción arqueológica de la memoria de los medios de Misiones.

Teniendo en cuenta lo esencial del concepto de método, debimos considerar la elección de técnicas a aplicar y principalmente en nuestra capacidad de modificar las técnicas existentes, adaptándolas al problema de investigación e incluso imaginar nuevas posibilidades. En tal sentido, una vez que un nuevo procedimiento o la modificación de alguna técnica son ideados, codificados y difundidos, se pueden convertir en técnicas disponibles para la comunidad de investigadores. Como científicos sociales sabemos que los resultados de nuestra investigación dependen en buena medida del trabajo y de las técnicas que apliquemos a nuestras fuentes. Es decir, del complejo de elecciones realizadas a lo largo de todo el recorrido.

Por las características de la información a relevar, utilizamos en principio técnicas que suponen la exploración de archivos, públicos y privados, aplicándose los procedimientos usuales en la investigación histórica. Pero también dimos fundamental importancia al rescate de los testimonios orales y a partir de ellos, a la construcción de fuentes orales/fílmicas. Este rescate de testimonios orales/fílmicos, prevé en una primera instancia precisar algunos criterios para proceder a la elección de los informantes calificados. La técnica de recolección de la información oral incluyó entrevistas semiestructuradas, con el fin de posibilitar que los informantes profundicen en el discurso y exterioricen sus vivencias: hilvanar historia y memoria. Teniendo en cuenta la intención de construir un archivo de fuentes orales/fílmicas, y considerando las posibilidades, registramos los testimonios mediante el uso de graba- 
dores y de equipos de filmación con el objetivo de comenzar a construir un archivo de registros fílmicos de las entrevistas.

Consideramos desde un punto de vista metodológico y técnico que la incorporación de la imagen como fuente sería de gran ayuda. Por tal motivo creemos discutible aquella premisa antigua que marcaba un conflicto entre la palabra y el poder de las imágenes y que privilegiaba a la primera por sobre la segunda. Sabemos que dentro de la cultura occidental, el lenguaje verbal siempre se mostró con mayor jerarquía por sobre la imagen. Podemos remitirnos a los tiempos bíblicos, a la Grecia Clásica con la alegoría de las cavernas de Platón, Ilegando a la actualidad con la desconfianza que despiertan los medios masivos de comunicación, muchas veces tildados de engañosos y manipuladores. No hay memoria sin imágenes, el conocimiento supone la necesidad de ver, aunque las imágenes no puedan proporcionar un conocimiento total. En este juego de historia y memoria, pareciera ser que la historia, con su supuesta objetividad y espíritu crítico se encuentra del lado de la palabra escrita (lenguaje) con un absoluto manejo correcto del tiempo humano; por otro lado, la memoria con su fragilidad y falta de confiabilidad estaría del lado de la imagen y el espacio. Evidentemente toda memoria depende de las imágenes que la mente evoca para luego traducirse a diversos medios de expresión. A pesar de los debates y discusiones sobre el lugar que ocupan historia/memoria, Andreas Huyssen sostiene que: "mientras que la historia y la memoria pueden pertenecer a registros discursivos diferentes, ninguna de las dos puede ser categóricamente separada de la otra." (Feld y Stites Mor, 2009:17) La propuesta es entonces reconocer que imágenes y palabras están entrelazadas en sus prácticas de representación, tal como la historia y la memoria deben ser reconocidas en una relación mutuamente constitutiva. Por supuesto que metodológicamente debemos tener definiciones disciplinarias más acotadas. La falla de la palabra puede ser complementada por la imagen y cuando la imagen se opaca, las palabras pueden brindar las significaciones ocultas dentro de un contexto complejo. Es fundamental considerar que allí donde tenemos ausencia de fuentes o imágenes documentales, se hace necesario crearlas (o recrearlas) utilizando todos los soportes, géneros y técnicas disponibles que nos permitan combatir a la evasión y principalmente al olvido ${ }^{22}$. Cuando nos referimos al len-

22 Cuestionamos la oposición tajante entre historia/memoria, historizando los escenarios de nuestra historia reciente y analizando las diferentes modalidades de testimonios. La intención siempre es reflexionar acerca del papel del lenguaje y la imagen (siem- 

RIA DE LOS MEDIOS EN LA PROVINCIA DE MISIONES: EL DOCUMENTAL COMO RESCATE DE LA HISTORIA Y MEMORIA DE LA TELEVISIÓN

guaje estamos hablando de un medio de expresión de la memoria: la declaración, el testimonio, la autobiografía, la fotografía, el cine, el documental, la televisión. Se trata de comprender las relaciones entre lenguaje verbal e imagen, historia y memoria, hecho y ficción. Como investigadores sociales jugamos sobre esos márgenes y en esos campos del conocimiento, evitando caer en la trampa que suele tendernos las cuestiones relacionadas con la memoria, esto es: creer en la completa autenticidad, en todo momento, de lo que narra el testigo ${ }^{23}$. Desde la segunda mitad del siglo XIX, el problema de la imagen como fuente preservadora de la memoria está presente en la investigación social. Boris Kossoy (2001) estudió este problema desde el punto de vista fotográfico señalando que el descubrimiento de la fotografía permitió el acceso al autoconocimiento y recuerdo, ya sea desde una óptica artística o de documentación y denuncia. Cualquier recorrido por el pasado no puede obviar la importancia de las imágenes y de la memoria. En nuestros días y en medio de lo que se conoce como "cultura de la memoria", las imágenes (capturadas por una cámara) adquieren una singular importancia. El pasado se nos brinda en imágenes de videos, fotos, documentales y programas de televisión. Estas imágenes se tornan en valiosos instrumentos de la memoria. En las postrimerías del siglo XX y ya entrado el siglo XXI, investigar y escribir sobre hechos históricos se convirtió en un equilibrio complicado. Según señala Enzo Traverso, este equilibrio se da sobre una cuerda suspendida entre dos temporalidades: "Por un lado, sus actores han adquirido, por su calidad de testigos, un estatus incuestionable de fuente para los investigadores; por el otro, estos últimos trabajan sobre una materia que interroga constantemente sus vivencias personales, cuestionando su propia posición." (Traverso, 2012:284) Investigar el pasado reciente convierte al historiador en un testigo directo e indirecto inmerso en un entramado de hilos que lo une al objeto de su investigación. Pero debemos dejar sentada una premisa fundamental: la investigación del pasado no es monopolio de los historiadores. Existen otros lugares para abordarlo como una fuente para construir relatos, legitimar acciones, establecer genealogías y hasta

pre en conjunto) en los diversos medios de comunicación que inciden en la rememoración del pasado.

23 Como historiadores no podemos cerrarnos y debemos permanecer abiertos a nuevas interpretaciones. Los archivos no están muertos, no son estables y siempre esperan las preguntas y las repreguntas. La memoria individual (y social) fluye y está en permanente debate. 
forjar identidades. El trabajo de investigación histórica constituye una forma específica de trabajar sobre el pasado. Pero sus producciones deben circular ( $y$ de hecho circulan) en ámbitos que trascienden la propia disciplina e interactúan en un espacio público.

\section{Rescatando la memoria en tiempos difíciles: el recurso del documental}

Reconstruir la memoria de un evento histórico a través de las imágenes y el sonido, tal fue la problemática teórico-metodológica que se nos presentó al encarar la investigación sobre LT 85 Canal 12. Como lo vinimos señalando, a partir de la década de 1970, el papel de la televisión fue fundamental como medio destinado a construir nacionalidad, identidad y ciudadanía en una zona fronteriza como lo es Misiones. Estas fueron algunas características que englobaron a la creación de la televisión pública provincial.

Además intentamos caracterizar el contexto histórico, político, social y cultural que permitió el surgimiento de la televisión en Misiones; la política comunicacional que la incluyó y las posibles resignificaciones que esa política sufrió a lo largo de la historia de este medio. Otra cuestión insoslayable fue examinar de qué manera el tema de la frontera y de la multiculturalidad estuvo presente en los fundamentos de las normas que dieron origen a la instalación de este medio. Pero también nos propusimos realizar tareas de construcción de fuentes. Es decir, buscar recursos metodológicos que permitieran la construcción de conocimientos sobre temas que posibilitaran, a su vez, discutir el papel de Canal 12 dentro de un contexto histórico nacional.

Fue así que surgió la idea de elaborar un documental sobre la participación de LT85 Canal 12, como institución comunicativa, en lo que algunos denominaron la "gesta de Malvinas", iniciada el 2 de abril de 1982. La propuesta de trabajo fue realizar un documental histórico que diera a conocer a la comunidad, el rol que tuvo el canal de televisión misionero en esos momentos tan caros a la historia argentina.

Desde abril de 1982, nuestro país vivió una situación histórica sin precedentes: la ocupación militar de las islas Malvinas. Este hecho conmovedor involucró directamente a la historia del canal de TV misionero. Entonces, ¿qué quisimos hacer?

En primer término, tratamos de reconstruir qué acontecimientos o circunstancias llevaron a un medio de comunicación ubicado en una provincia 
LA CONSTRUCCIÓN DE FUENTES PARA RECONSTRUIR LA HISTORIA DE LOS MEDIOS EN LA PROVINCIA DE MISIONES: EL DOCUMENTAL COMO RESCATE DE LA HISTORIA Y MEMORIA DE LA TELEVISIÓN

fronteriza, distante de la zona del conflicto, a participar de forma activa, aportando tecnología y recursos humanos para instalar una estación de TV.

De esta forma, la idea fue preparar un guión central, histórico-cronológico, sobre el cual se enlazaran los testimonios de aquellos que protagonizaron este hecho. El trabajo metodológico de fondo consistió en hilvanar memoria e historia. Quisimos resaltar entre otros temas, las vivencias personales y profesionales de los protagonistas y el rol de Canal 12 como institución y como medio de comunicación.

Recordemos que LT85 Canal 12 salió al aire de Misiones por primera vez un 18 de noviembre de 1972. Por lo tanto, al desencadenarse los hechos de Malvinas, la televisión pública misionera contaba con menos de 10 años de existencia. Así, a pesar de su juventud, el canal y su personal asumió la responsabilidad de trasladarse a las islas e instalar la primera emisora de televisión argentina en aquel territorio. Todo esto más allá de las implicancias políticas del momento ya que la orden había sido emitida y el gobierno provincial, a cargo por aquel entonces del general (RE) Juan M. Bayón, no hizo otra cosa más que obedecer a la superioridad.

Nuestro objetivo fue focalizar a través del material fílmico, la experiencia del personal del canal (memoria), qué sintieron y cómo fueron esos días que pasaron en el terreno del conflicto. La pregunta metodológica de rigor fue cómo organizar el material para obtener un producto que nos permita abordar este tema histórico desde un punto de vista más amplio, es decir, desde el proyecto de investigación histórica, elaborar un trabajo heurístico, pero con posibilidades de divulgación hacia la comunidad en general (extensión).

Así, delimitado el tema y planteados algunos problemas preliminares nos decidimos por realizar el documental.

Dentro de los problemas preliminares surgieron algunos relacionados a temas conceptuales y teóricos. En tal sentido, lógicamente si estamos analizando la historia de la televisión, el formato del documental debe ser televisivo e histórico. A partir de aquí ya se nos presentan las primeras cuestiones: ¿qué es un documental? ¿Qué tipos de documentales existen? ¿Cuáles son las características de un documental histórico? Y finalmente ¿qué es un documental de divulgación histórica? Justamente, este aspecto teórico-metodológico viene a jugar un rol fundamental en nuestro trabajo, el cual reviste un doble enfoque: histórico y comunicativo.

En el sentido en que lo utilizamos, una muy breve aproximación etimo- 
lógica del término documental alude al vocablo inglés documentary. Dicha expresión habría sido utilizada por primera vez en el ambiente cinematográfico por el crítico británico John Grierson. En 1926, este autor, haciendo referencia a la película Moana de Robert Flaherty, le daba a la misma un "valor documental". Sin embargo, recién para 1989, el Oxford English Dictionary introdujo a la acepción documentary una relación con la película documental refiriéndose a hechos realistas aplicados a una película o trabajo literario (Hernández Corchete, 2008).

En castellano, la palabra documental pasó desde el siglo XIX a tener un único significado: "Que se funda en documentos o se refiere a ellos". Por otra parte, desde 1956, el Diccionario de la Lengua Española ya había incorporado el sentido cinematográfico al término. Ya en 1992, se amplía el concepto hacia los programas televisivos. Por último, desde el 2001 la Real Academia añadió a la finalidad informativa del documental un sentido didáctico (Hernández Corchete, 2008).

Las raíces históricas de este género están fundadas en las necesidades políticas y sociales de cada momento. Además, se deben considerar también en perspectiva histórica las permanentes innovaciones tecnológicas y la creatividad por parte de los realizadores. Sin duda, el primer género documental fue el cinematográfico. Al respecto, ya mencionamos el aporte del documentalista estadounidense Robert Flaherty quien señaló el camino con su obra Nanuk el esquimal a comienzos de la década de 1920. Flaherty es considerado como el "padre del documental" ya que inició por ese entonces una corriente documental cinematográfica con características etnográficas.

En forma simultánea a este movimiento documentalista, se desarrolló en la antigua URSS otro género similar cinematográfico. La tradición propagandística soviética había surgido luego de la Revolución de $1917^{24}$. Esta forma de documental cinematográfico sirvió como herramienta para educar y adoctrinar al pueblo sobre el comunismo. En tal sentido se destaca la labor del director ruso Dziga Vertov quien aportó innovaciones interesantes en este tipo de trabajo cinematográfico. Hacia comienzos de la década de 1930 podemos señalar el aporte del documentalista británico Paul Rotha quien sostenía que el documental era un medio cinematográfico destinado a interpretar creativamente la realidad. Así, la lista de directores se va incrementando con el paso de las décadas y la tecnología irá aportando a 

TAL COMO RESCATE DE LA HISTORIA Y MEMORIA DE LA TELEVISIÓN

las ideas para transformar el campo. Surgen entonces nuevas tipologías documentales dentro de la industria cinematográfica: el cinéma verité y el direct cinéma que se nutren de nuevas teorías ${ }^{25}$. Cualquiera sea la tipología, el documental cinematográfico presenta una naturaleza argumentativa que lo separa definitivamente de la ficción. El documental apunta siempre hacia una argumentación relacionada con el mundo histórico. El argumento debe ser un compromiso retórico y convincente. Las funciones de este género se basan en grabar, revelar, analizar, preservar, interrogar y expresar. Durante mucho tiempo, el género documental cinematográfico contó con una intensidad de naturaleza persuasiva hacia el espectador. Muchas de las corrientes tenían una clara marca instructiva y sociopolítica, sin detrimento de la función de entretener. Pero también, vimos que otras corrientes se orientaron hacia modalidades tales como la antropológica o etnográfica dando origen a películas como las de Robert Flaherty.

\section{El documental y la televisión: investigar para divulgar}

Luego de la Segunda Guerra Mundial, con el auge de la TV, el género documental se irá separando del género cinematográfico. Así se irán afianzando más los aspectos informativos y periodísticos que los estéticos. El género televisivo busca más la actualidad informativa. Por otra parte, las mejoras introducidas en el soporte televisivo, por ejemplo, el tratamiento electrónico o informático de las imágenes, posibilitó nuevas experiencias narrativas. En el documental televisivo, el documentalista se dirige directamente al espectador. Son varios los documentos utilizados. Hay producciones que además de utilizar imágenes de archivo, muestran imágenes propias grabadas por los reporteros los que también suelen armar los guiones. Haciendo la separación entre reportaje de actualidad y documental, podemos decir que un documental busca lo permanente, la sedimentación que va dejando la vida cotidiana. Se interna en la realidad para lograr un conocimiento más global y duradero. El documental se centra en lo perdurable. De allí, nuestro interés en este género como herramienta heurística.

El documental de divulgación tiene una función formativa y/o educativa. ¿Qué se entiende por divulgación? Podríamos afirmar que se trata de comunicación especializada establecida entre científicos y el público en ge-

25 Por ejemplo, prescindir de guiones, actores y decorados, mostrando las secuencias tal como aparecen en realidad. 
neral. O también podemos decir que divulgación es solo aquella que se lleva a cabo fuera de la enseñanza oficial o de sus equivalentes. Un documental de divulgación en principio busca profundizar en la transmisión de conocimientos más atemporales sobre arte, literatura, historia, geografía, folclore, antropología, naturaleza, ciencia y tecnología, etc.

¿Quiénes componen la audiencia? No es un grupo de expertos, tampoco una comunidad con un interés específico en el conocimiento de un tema determinado. Se trata de un conjunto heterogéneo de personas profanas en la materia y que se acercan a la TV en busca de distracción y entretenimiento. Por lo tanto, el discurso narrativo no debe acercarse a un discurso científico propiamente, más bien debe emplear otro tipo de discurso que se conecte más con las formas de entendimiento de las grandes audiencias y aquí es fundamental el papel del comunicador quien trabaja en forma conjunta con el historiador investigador.

El documental de divulgación no está concebido como un estudio sistemático que permita un diálogo exhaustivo entre especialistas, acerca de las cuestiones que plantea. El principal objetivo es transmitir una serie de conocimientos básicos a un público inexperto, desde un punto de vista particular: el del realizador. La fuente histórica así construida presenta algunas de las tres características que tiene un documental: a) representación y explicación con planos tomados de la realidad. De modo excepcional reconstrucciones veraces de acontecimientos originados en el mundo histórico; b) interpretación de la realidad mostrada a través de la participación de narradores, testigos, selección y montaje de imágenes y sonidos; c) preocupación artística o estética del documentalista. El material fílmico realizado bajo el título "Canal 12 en Malvinas: Crónica del canal misionero en las Islas" posee algunas connotaciones de un documental de divulgación histórica. Básicamente constituyó parte de nuestra investigación y refleja un intento por construir fuentes históricas de diferente naturaleza: el trabajo con imagen y sonido. Si bien el trabajo puede ser catalogado como un documental de divulgación histórica, el mismo tiene ciertas particularidades que lo distinguen. Por ejemplo, si bien reconstruye un conjunto de acontecimientos pasados y dignos de memoria, el mismo fue realizado en su mayoría con material fílmico propio, es decir que se grabaron (y desgrabaron) todas las entrevistas realizadas a nuestros informantes. En tal sentido fuimos los realizadores quienes hicimos el trabajo crítico y de interpretación de las fuentes a través de la selección y proyección de imágenes. Por otra parte, 
LA CONSTRUCCIÓN DE FUENTES PARA RECONSTRUIR LA HISTORIA DE LOS MEDIOS EN LA PROVINCIA DE MISIONES: EL DOCUMENTAL COMO RESCATE DE LA HISTORIA Y MEMORIA DE LA TELEVISIÓN

los testimonios grabados en video, fueron tratados como fuentes orales y como tales recibieron el procedimiento técnico y metodológico utilizado en la ciencia histórica cuando se trata de esta tipología de fuentes/testimonios.

\section{REFLEXIONES FINALES}

La provincia de Misiones, ubicada estratégicamente en una región que limita con dos países (Paraguay y Brasil) posee una historia que se remonta hasta inicios del siglo XVII. Como hemos visto, en materia de sus medios de comunicación no tenemos que discurrir tantos siglos. Constituido en Territorio Nacional (1881) Misiones ya contaba con algunos medios gráficos y entrado el siglo XX en forma gradual, la historia se fue enriqueciendo con la llegada de la radio y posteriormente la televisión. Así, desde el campo científico de la comunicación social y la historia decidimos encarar el proyecto de hacer la historia de los medios de comunicación misioneros. Si bien la tarea es difícil y compleja no deja de ser apasionante y constituye un verdadero desafío desde el punto de vista histórico-metodológico.

El historiador oscila entre dos posiciones historiográficas. Por un lado lo real como conocido, es decir, el objeto de conocimiento histórico construido, y lo real como implicado por la operación científica que incluye a la sociedad actual, a los procedimientos utilizados, formas de comprensión y práctica del sentido. Estas dos realidades no pueden eliminarse ni reducirse entre sí. Allí, en esa compleja relación, se apoya la ciencia histórica. Su primer objetivo es desarrollar esta relación en un discurso. Entendemos que existe un tipo de historia que se interroga sobre lo "pensable" y sobre las condiciones objetivas de su comprensión y otro que pretende arribar a lo "vivido", sacarlo a la luz gracias al conocimiento del pasado. Esto nos lleva a la reflexión de convertir en pensables a los documentos hallados, a la necesidad de elaborar modelos que posibiliten construir para comprender series de documentos (modelos económicos, culturales, etc.) En la actualidad, esta perspectiva metodológica lleva al historiador a revisar sus hipótesis de trabajo, a plantearse posibilidades de intercambios interdisciplinares capaces de establecer pertinencias y producir "hechos". La historia siempre se desarrolla en las fronteras donde la sociedad une su pasado con el presente y con el acto que lo distingue: la operación histórica. Desde la segunda mitad del siglo XX, los historiadores como practicantes del oficio, vieron crecer re- 
giones silenciosas donde antes estaban ausentes. Así surgieron nuevos límites hasta donde moverse en materia de investigación y creación de discurso histórico : "Pase lo que pase con las posiciones propias del autor, su obra describe y precipita el movimiento que lleva a la historia a convertirse en un trabajo sobre el límite: a situarse en relación con otros discursos (...) pero también a establecer continuidades al aislar las series, a precisar métodos al distinguir los distintos objetos que se captan en un mismo hecho, a revisar y a comparar las periodizaciones diferentes que hacen aparecer diversos tipos de análisis, etcétera." (De Certeau 2006:56) Entonces, el problema metodológico se mueve, ya no está en la tradición y en las huellas (vestigios) sino en la división y el límite.

Transitando la segunda década del siglo XXI, estos conceptos operatorios dentro del campo historiográfico se vuelven instrumentos de trabajo y a la vez lugar de examen metodológico. 
LA CONSTRUCCIÓN DE FUENTES PARA RECONSTRUIR LA HISTORIA DE LOS MEDIOS EN LA PROVINCIA DE MISIONES: EL DOCUMENTAL COMO RESCATE DE LA HISTORIA Y MEMORIA DE LA TELEVISIÓN

\section{REFERÊNCIAS}

Aceves Lozano, Jorge (comp.) (1993) Historia Oral. México. Instituto de Investigaciones Dr. José maría Luis Mora.

Carnovale, Vera (2007) “Aportes y problemas de los testimonios en la reconstrucción del pasado reciente en la Aregentina" en: Franco, Marina y Levin, Florencia (comps) Historia reciente. Perspectivas y desafíos para un campo en construcción. Buenos Aires, Paidós. (pp. 155-181)

De Certeau, Michel (2006) La escritura de la historia. México, Universidad Iberoamericana, Instituto Tecnológico y de Estudios Superiores de Occidente.

Feld, Claudia y Stites Mor, Jessica (comps.)(2009) El pasado que miramos. Memoria e imagen ante la historia reciente. Buenos Aires, Paidós.

Hernández Corchete, Sira (2008) La historia contada en televisión. El documental televisivo de divulgación histórica en España. Barcelona, Gedisa.

Kossoy, Boris (2001) Fotografía e historia. Buenos Aires, La marca.

Traverso, Enzo (2011) El pasado, instrucciones de uso. Buenos Aires, Prometeo.

Traverso, Enzo (2012) La historia como campo de batalla: Interpretar las violencias del siglo XX. Buenos Aires, Fondo de Cultura Económica.

Fuente audiovisual

García Da Rosa, Carlos y Pyke, Jorge N. (2012) Canal 12 en Malvinas: Crónica del canal misionero en las Islas (Video). Posadas. LT85 TV Canal 12 Misiones.

RECEBIDO EM: 16/05/2015

ACEITO PARA PUBLICAÇÃO: 02/07/2015 


\section{Jorge Nelson Pyke}

Licenciado en Historia y Magíster en Antropología Social, Facultad de Humanidades y Ciencias Sociales de la Universidad Nacional de Misiones. Docente Investigador de la carrera de Historia de la Facultad de Humanidades y Ciencias Sociales UnaM. 
